\title{
VARIATIONS WITH AGE IN THE NUMBER OF ACTIVE PALMAR DIGITAL SWEAT GLANDS
}

BY

\author{
PAMELA C. B. MACKINNON
}

From the Department of Anatomy, Middlesex Hospital Medical School, London

Acute emotion to which a response is made has been found to result in an increase of palmar sweat activity (Kuno, 1934), but tensional states in which responses are suppressed result in a decrease in activity (Van der Valk and Groen, 1950). This psychosomatic function of the palmar sweat glands can be recorded either by electrical skin resistance or by direct sweat prints, and is now being increasingly used in psychiatry (Bitterman and Holtzman, 1952; Van der Valk and Groen, 1950 ; Seitz and Shipley, 1952).

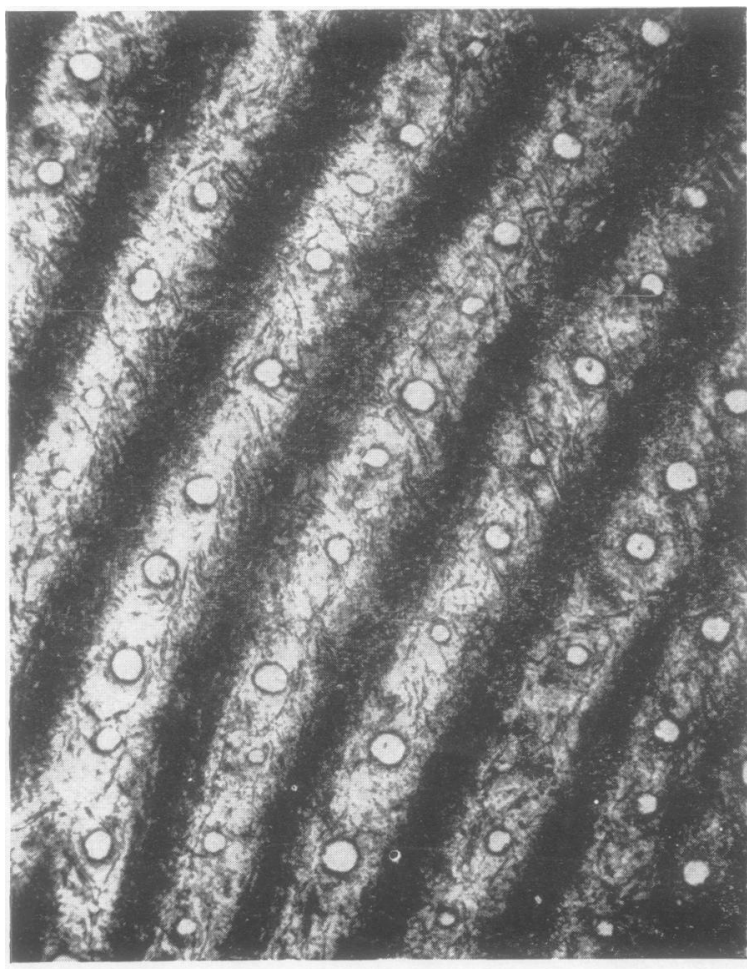

Palmar sweat activity is an indicator not only of these emotional changes but also of autonomic activity, and sweating tests have also been used in neurology (Regelsberger, 1949 ; Malis, Grynbaum, and Bierman, 1949), proving useful in the diagnosis of early nerve lesions (Kahn, 1951).

Accurate assessment of the information obtained from these tests is not possible unless the gerontological effect on palmar sweating is taken into account.

The object of this paper was to investigate this effect statistically.

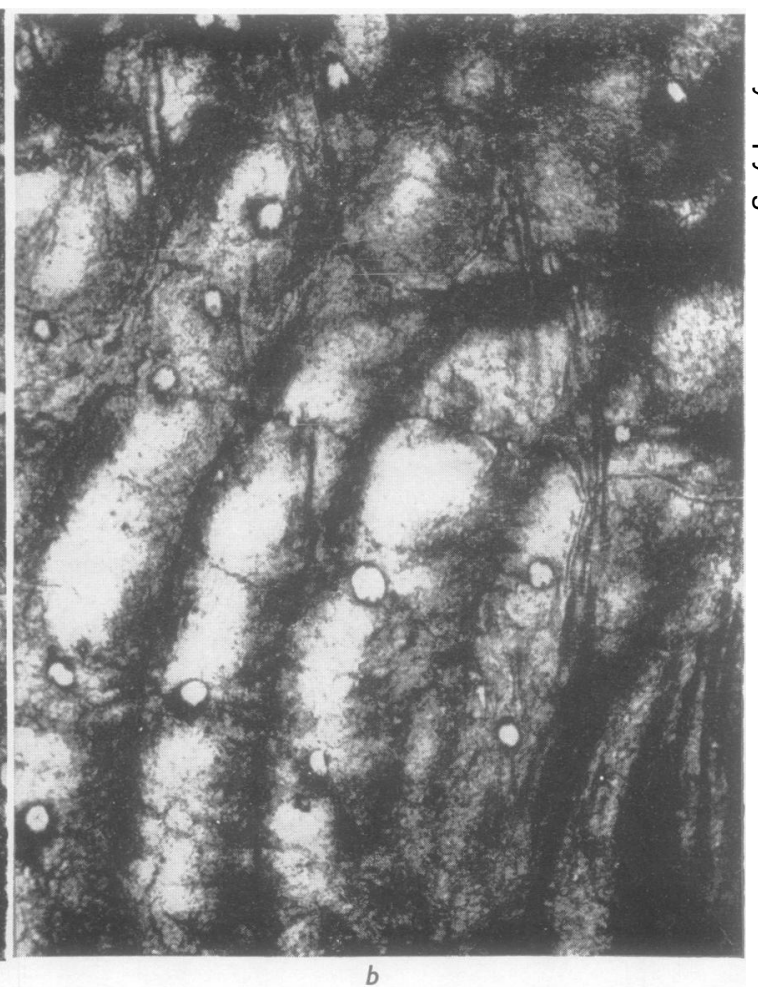

b

Fig. 1.-Plastic impressions of finger pad in (a) boy aged 15 years and $(b)$ man aged 88 years showing " pores" of active sweat glands (both $\times 50)$. 


\section{Method}

Records of active sweat glands in the pad of the right middle finger were obtained from 123 healthy males comprising 20 schoolboys, 54 firemen, and 49 Chelsea pensioners. The age range was 7 to 96 years.

The technique used was that of Sutarman and Thomson (1952). The pad of the right middle finger was blotted carefully to remove excess sweat and a layer of plastic paint applied ; this dried within a few seconds and was removed by the application of a strip of "sellotape". The paint held a record of the finger print, active sweat glands showing as " pores" along the ridges (Fig. 1).

Every subject was seated for half an hour before and during the test which took place between 2.15 and 3.15 p.m. The object and procedure of the tests were explained to eliminate as far as possible any emotional tension. Room temperatures varied between $60^{\circ}$ and $67^{\circ} \mathrm{F}$. with an average of $65^{\circ} \mathrm{F}$., except for subjects in the sixth decade for whom it was between $67^{\circ}$ and $73^{\circ} \mathrm{F}$.; relative humidity varied between $48 \%$ and $55 \%$ with an average of $50 \%$.

Counts of the number of active sweat glands in a unit area of $4 \mathrm{sq}$. $\mathrm{mm}$. immediately distal to the central whorl were made under a magnification of 10 . This area was constantly used because of variation in the number of glands from area to area (Randall, 1946).

Owing to the fact that skin stretches with growth, the number of sweat glands in a unit area of skin in the first two decades will be falsely high compared with the number after growth has ceased, and for this reason a correction was made to the figures of the first two decades as follows :

Heights and weights of all subjects were taken and their surface area calculated ; each count was then multiplied by the surface area of the subject and divided by the surface area of an average adult male $(1.73 \mathrm{sq} . \mathrm{m}$.), it being presumed that the surface area of a finger increases with growth to the same extent as the rest of the body.

\section{Results}

The table contains counts of the number of active sweat glands in the unit area of 123 males, arranged in single columns containing two consecutive decades. In addition it contains the arithmetic mean for each two consecutive decades and their standard deviations. It shows considerable variation between individual counts as well as a decrease in the average counts between each two consecutive decades.

Fig. 2 depicts the arithmetic means of the counts for each two consecutive decades in graphic form. It shows that the counts fall from a maximum of 100 during the first and second decades to a minimum of 14 in the ninth and tenth decades, almost half the drop occurring between the first and second, and third and fourth decades. Statistical significance was shown between the means of each two consecutive decades in that their difference was found to exceed twice the standard error of their means (Hill, 1950).
TABLE

NO. OF ACTIVE SWEAT GLANDS IN 4 SQ. MM. OF PAD OF RIGHT MIDDLE FINGER IMMEDIATELY DISTAL TO CENTRAL WHORL IN RELATION TO AGE

\begin{tabular}{|c|c|c|c|c|c|c|c|c|c|}
\hline \multicolumn{2}{|c|}{$\begin{array}{l}\text { 1st and } 2 \text { nd } \\
\text { Decades }\end{array}$} & \multicolumn{2}{|c|}{$\begin{array}{l}\text { 3rd and 4th } \\
\text { Decades }\end{array}$} & \multicolumn{2}{|c|}{$\begin{array}{l}5 \text { th and 6th } \\
\text { Decades }\end{array}$} & \multicolumn{2}{|c|}{$\begin{array}{l}7 \text { th and } 8 \text { th } \\
\text { Decades }\end{array}$} & \multicolumn{2}{|c|}{$\begin{array}{l}\text { 9th and 10th } \\
\text { Decades }\end{array}$} \\
\hline Age & Counts & Age & Counts & Age & Counts & Age & Counts & Age & Counts \\
\hline $\begin{array}{r}7 \\
8 \\
9 \\
10 \\
11 \\
12 \\
13 \\
13 \\
13 \\
13 \\
14 \\
15 \\
15 \\
15 \\
15 \\
17 \\
17 \\
17 \\
18 \\
18 \\
- \\
- \\
- \\
- \\
- \\
-\end{array}$ & $\begin{array}{r}121 \\
149 \\
100 \\
126 \\
73 \\
43 \\
100 \\
148 \\
144 \\
107 \\
102 \\
9 \\
103 \\
90 \\
92 \\
112 \\
144 \\
96 \\
85 \\
45 \\
- \\
- \\
- \\
- \\
- \\
- \\
-\end{array}$ & $\begin{array}{l}23 \\
24 \\
24 \\
25 \\
25 \\
26 \\
26 \\
27 \\
27 \\
27 \\
28 \\
28 \\
29 \\
29 \\
30 \\
31 \\
31 \\
31 \\
31 \\
32 \\
32 \\
34 \\
34 \\
35 \\
36 \\
56 \\
38 \\
38 \\
39\end{array}$ & $\begin{array}{r}97 \\
63 \\
88 \\
68 \\
139 \\
108 \\
58 \\
68 \\
50 \\
60 \\
29 \\
14 \\
79 \\
59 \\
78 \\
66 \\
67 \\
54 \\
21 \\
71 \\
19 \\
4 \\
79 \\
84 \\
27 \\
58 \\
27 \\
56 \\
28\end{array}$ & $\begin{array}{l}40 \\
40 \\
40 \\
41 \\
42 \\
43 \\
43 \\
44 \\
44 \\
44 \\
45 \\
45 \\
46 \\
46 \\
47 \\
48 \\
48 \\
48 \\
49 \\
52 \\
53 \\
56 \\
58 \\
59 \\
59 \\
- \\
- \\
-\end{array}$ & $\begin{array}{r}63 \\
47 \\
23 \\
49 \\
27 \\
61 \\
53 \\
35 \\
49 \\
43 \\
45 \\
75 \\
15 \\
31 \\
47 \\
59 \\
12 \\
22 \\
6 \\
50 \\
28 \\
65 \\
82 \\
39 \\
39 \\
- \\
- \\
\end{array}$ & $\begin{array}{l}60 \\
60 \\
63 \\
65 \\
65 \\
66 \\
66 \\
67 \\
67 \\
67 \\
67 \\
68 \\
69 \\
69 \\
70 \\
70 \\
72 \\
72 \\
73 \\
74 \\
75 \\
75 \\
76 \\
77 \\
77 \\
78 \\
79 \\
79 \\
-\end{array}$ & $\begin{array}{r}30 \\
59 \\
10 \\
35 \\
24 \\
10 \\
15 \\
33 \\
71 \\
11 \\
12 \\
104 \\
16 \\
7 \\
11 \\
23 \\
54 \\
7 \\
4 \\
76 \\
11 \\
45 \\
18 \\
9 \\
16 \\
5 \\
22 \\
10 \\
-\end{array}$ & $\begin{array}{l}80 \\
80 \\
80 \\
80 \\
81 \\
81 \\
82 \\
83 \\
83 \\
84 \\
84 \\
85 \\
87 \\
87 \\
88 \\
89 \\
89 \\
90 \\
90 \\
96 \\
96 \\
- \\
- \\
- \\
- \\
- \\
-\end{array}$ & $\begin{array}{r}56 \\
29 \\
34 \\
4 \\
37 \\
13 \\
9 \\
16 \\
13 \\
13 \\
8 \\
13 \\
4 \\
20 \\
31 \\
16 \\
8 \\
24 \\
4 \\
4 \\
0 \\
- \\
- \\
- \\
- \\
- \\
-\end{array}$ \\
\hline Means & 100 & \multicolumn{2}{|r|}{59} & \multicolumn{2}{|r|}{45} & \multicolumn{2}{|r|}{27} & \multicolumn{2}{|r|}{14} \\
\hline S.D. & 42 & \multicolumn{2}{|r|}{33} & \multicolumn{2}{|r|}{15} & \multicolumn{2}{|r|}{20} & \multicolumn{2}{|r|}{17} \\
\hline
\end{tabular}

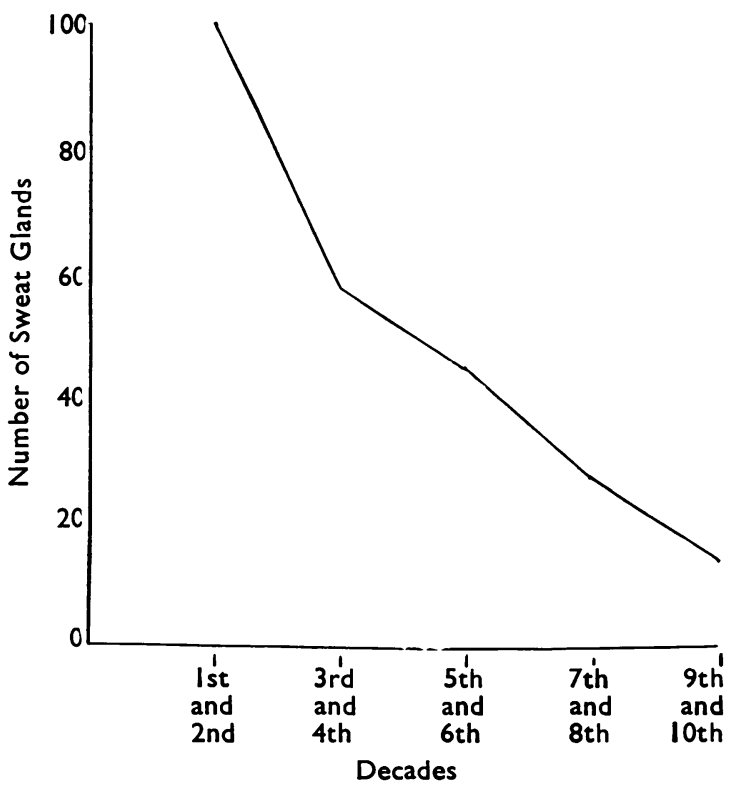

Fig. 2.-Average number of sweat glands for each two consecutive decades. 


\section{Discussion}

Burch, Cohn, and Neumann (1942) investigated the rate of water loss from the finger tips in eight senile persons and found it to be considerably lower than in younger persons; this they ascribed to the reduced physiological activity of senility. Van der Valk and Groen (1950) also reported a decreased activity with age, but neither of these authors noted the rapid decrease which occurs in the early decades.

Reduced physiological activity of old age is dependent on several factors, the most important of which are decrease in blood supply, degeneration of the nervous controlling mechanism, and intrinsic degeneration of the glands, the last factor being a constant feature of all organs in senility.

Decreased blood supply occurs with advancing atherosclerosis or with vasoconstriction coincident upon a lowered basal metabolic rate and body temperature. But constriction of the blood supply to an arm has been shown to have no constant effect on palmar sweating (Richter and Whelan, 1943) and List and Peet (1938) have stated that sweating is not dependent on the normal circulation of the blood. It appears unlikely, therefore, that a decreased blood supply to the glands would have any great effect on activity, especially in the early decades.

Degeneration of the nervous controlling mechanism of the glands occurs and has been described in the cerebrum (Riese, 1946), spinal cord (Gardner, 1940), and ganglia of the sympathetic chain (Kuntz, 1938). Subsequent degeneration of the nerve cell fibres with resultant fibrosis would lead to fewer impulses reaching the sweat glands and therefore decreased activity as age progresses.

These factors, although they contribute to a decreased activity in the later decades, do not explain the reason for the maximum rate of decrease occurring during the early decades. A possible explanation of this phenomenon may lie in the activity of the suprarenal cortex, for it has been suggested that a decrease in palmar sweat activity occurs with increased corticoid production (Van der Valk and Groen, 1950 ; MacKinnon, in the press).

During the early decades of life when the body is encountering many new stresses corticoid production will be high, resulting in a rapid decrease of the initially high palmar sweat secretion. In the middle decades an adaptive reaction to constant stresses occurs (Selye, 1950) modifying the suprarenal cortical output, which in turn may modify the steep decline of palmar sweating.

\section{Summary}

Counts of active palmar digital sweat glands in 4 sq. $\mathrm{mm}$. of the right middle finger immediately distal to the central whorl were obtained in 123 healthy males under similar conditions.

Counts were shown to be significantly lower between each two consecutive sets of decades, the maximal rate of decrease in numbers occurring between the first and second and third and fourth decades.

It is suggested that (a) the maximal rate of decrease in the early decades is due mainly to high corticoid production ; $(b)$ that the slower rate of decrease in the later decades is due to a modified corticoid production and a general reduction of physiological activity.

I wish to thank Col. F. M. Lipscomb, O.B.E., F.R.C.P., the Royal Hospital Authorities, Mr. C. S. Walton, M.A., Headmaster of University College Senior School, Mr. C. E. Vogel, M.A., Headmaster of University College Junior School, and the Chief Fire Officer of the London Fire Brigade for their cooperation without which this work could not have been performed; Professor E. W. Walls for his helpful criticism, and Mr. P. Runnicles for the photographs.

\section{REFERENCES}

Bitterman, M. E., and Holtzman, W. H. (1952). J. abnorm. soc. Psychol., 47, 615.

Burch, G. E., Cohn, A. E., and Neumann, C. (1942). Amer. Heart J., $23,185$.

Gardner, E. (1940). Anat. Rec., 77, 529.

Hill, A. Bradford (1950). Principles of Medical Statistics, 5th ed., p. 118. The Lancet Ltd., London.

Kahn, E. A. (1951). Surg. Gynec. Obstet., 92, 22.

Kuno, Y. (1934). The Physiology of Human Perspiration, 1st ed., p. 129. Churchill, London.

Kuntz, A. (1938). Amer. J. Path. 14, 783.

List, C. F., and Peet, M. M. (1938). Arch. Neurol. Psychiat. Chicago, $39,1228$.

MacKinnon, P. C B. (1954). J. Obstet. Gynaec. Brit. Emp. In the

Malis, Lress. Grynbaum, B. B., and Bierman, W. (1949). Arch. phys. Med., $30,763$.

Randall, W.' C.'(1946). J. clin. Invest. 25, 761.

Regelsberger, H. S. (1949). Klin. Wschr., $27,437$.

Richter, C. P., and Whelan, F. (1943). J. Neurophysiol., 6, 191.

Riese, W. (1946). J. Neuropath., 5, 160.

Seitz, P. F. D., and Shipley, R. E. (1952). J. invest. Derm., 19, 49.

Selye, H. (1950). "Stress", Acta Montreal, ist. ed., p. 101.

Sutarman, - and Thomson, M. L. (1952). J. Physiol. 117, s1P.

Van der Valk, J. M., and Groen, J. (1950). Psychosem. Med., 12, 303. 